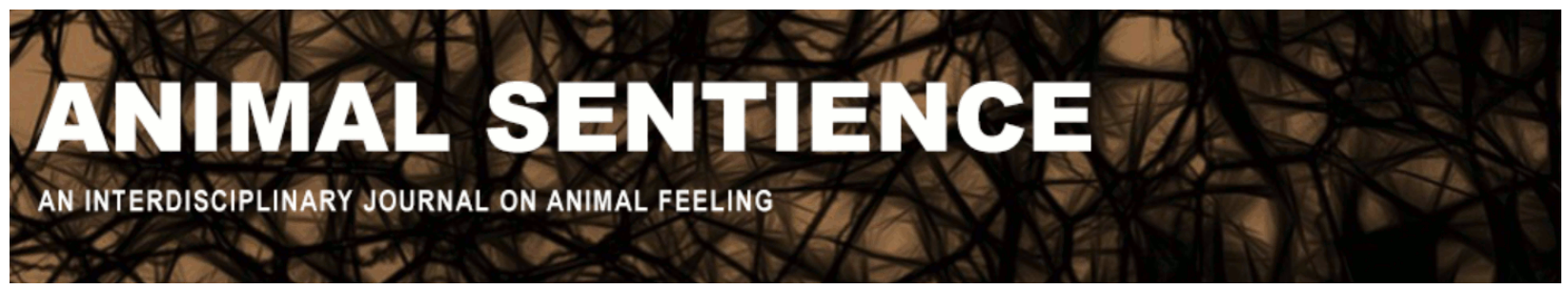

Levy, Neil (2020) It might not matter very much whether insects are conscious. Animal Sentience 29(2)

DOI: $10.51291 / 2377-7478.1583$

Date of submission: 2020-06-09

Date of acceptance: $2020-06-10$

(c)

This article has appeared in the journal Animal

Sentience, a peer-reviewed journal on animal

cognition and feeling. It has been made open access,

free for all, by WellBeing International and deposited

in the WBI Studies Repository. For more information,

please contact

wbisr-info@wellbeingintl.org.

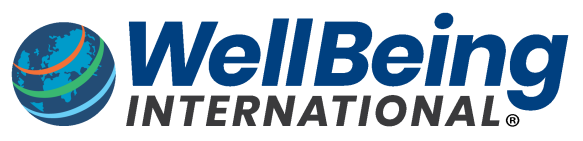

SOLUTIONS FOR PEOPLE, ANIMALS AND ENVIRONMENT 


\title{
It might not matter very much whether insects are conscious
}

Commentary on Mikhalevich \& Powell on Invertebrate Minds

\author{
Neil Levy \\ Department of Philosophy, Macquarie University \\ Uehiro Centre for Practical Ethics, University of Oxford
}

\begin{abstract}
In common with most other authors, Mikhalevich \& Powell assume that phenomenal consciousness is a "precondition" of moral standing. Although the evidence they present makes it much more likely than usually thought that arthropods are phenomenally conscious, scepticism in the face of this evidence remains intellectually respectable. I suggest that we best make progress here by rejecting the notion that phenomenal consciousness is necessary for moral standing. Mental states that may lack phenomenal properties can do a lot of work in grounding moral standing, and there is less room for scepticism about these mental states than about phenomenal consciousness.
\end{abstract}

Neil Levy, Professor of Philosophy, Macquarie University, Sydney, and senior research fellow, Uehiro Centre for Practical Ethics, University of Oxford, is the author of 7 books, including Consciousness and Moral Responsibility (Oxford University Press). Website

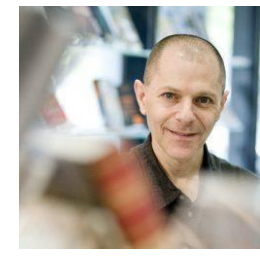

"Phenomenal consciousness" (or "sentience") refers to the qualitative feeling associated with some mental states. There is something it is like to be in these states: felt qualities are associated with listening to music, smelling flowers, maddening itches, and so on. While almost no one is sceptical that other normal human beings are phenomenally conscious, there is extensive debate about agents in pathological states (e.g., those in persistent vegetative states) and about other animals.

These debates matter because phenomenal consciousness matters. It matters because phenomenal states seem to be intrinsically pleasant or unpleasant. Pain and pleasure are the obvious examples. Being in pain feels bad, and for that reason, to the extent to which someone is in pain, their life is going worse than it would otherwise; the reverse is true for pleasure, because it feels good. So knowing whether humans in pathological states or non-human animals are phenomenally conscious is important: it matters to how we should treat them.

Debates over humans in pathological states remain unresolved, but there is a near consensus among scientists over the phenomenal consciousness of mammals and some other animals. Nearly a decade ago, the Cambridge Declaration on Consciousness (Low et al. 2012) summed up this consensus: consciousness extends beyond humans to mammals and birds "and many other creatures". But which other creatures? The declaration explicitly mentions only octopuses. There is increasing acceptance that other cephalopods are phenomenally conscious too. But there is little willingness to ascribe consciousness to invertebrates.

Focusing on arthropods, Mikhalevich \& Powell (2020) (M\&P) set out to challenge this assumption. Those who deny that arthropods are conscious are usually ignorant of their cognitive 
complexity. It is very likely that this ignorance helps explains why most people are confident that they are not conscious: we think of them as simple automata, whose behaviour consists of stereotypies and reflexes. The evidence M\&P review for the existence of cognitive capacities like numerosity and the capacity to discriminate stimuli with no conceivable analogues in the environment to which they're adapted (like impressionist versus cubist paintings) testifies to the complexity and flexibility of arthropod cognition.

As M\&P note, however, it remains possible to deny that arthropods are conscious in the face of this evidence. This would not be just idle scepticism, of the sort that points to the logical possibility that other people do not possess minds and concludes that we can't know that we're not the sole thinking beings in the universe. Since we have excellent reason to think that minds, including their phenomenal states, are realized by brains, and we know that other humans and many other animals too have brains like ours, we have reason to think that they have minds like ours. But we don't have such reasons with regard to arthropods. Their brains are very different from ours, so we lack grounds for this argument from analogy. Things would be different if we were in possession of a well-founded and detailed neurofunctional account of consciousness, on the basis of which we could assess whether structures in arthropod brains played the right roles to realize consciousness. Although there are plenty of proposals around (the Global Workspace Theory (Baars 2005), Integrated Information Theory (Tononi et al. 2016) and so on), none have achieved consensus.

In the face of this problem, M\&P point to influences on our thought that might illicitly lead us to deny consciousness to arthropods (the disgust response, the unjustified belief that they lack complex cognition, and so on) and suggest that we ought to be less sceptical. They also point to moral risks here: false negatives have moral costs (in terms of the imposition of suffering, for example) that false positives lack, and urge us to assign significant weight to the possibility that arthropods are conscious in making decisions. All of that is well taken. But there is reason to think we can go further.

M\&P accept the near universal view that phenomenal consciousness is "a precondition for moral standing". It's this assumption that makes trouble, because we lack a detailed understanding of the neural correlates of phenomenal consciousness. Fortunately, there are good reasons to reject the assumption. Perhaps phenomenal consciousness is sufficient for moral standing, but it is not a precondition.

Much of the work done by appeals to phenomenal consciousness can in fact be done by functionalizable properties of the mind. Kahane \& Savulescu (2009) argue, for example, that phenomenal consciousness is important because it is required for having a point of view. But that's surely false: having a point of view requires some sort of cognitive unity and executive function, not phenomenality. Seager (2001) argues that only phenomenally conscious beings can value things. But that too seems false: having beliefs and goals seems sufficient for valuing states of affairs, and these are functionalizable states.

More generally, there are good reasons to think that what our mental states feel like to us (if anything) plays only a minor role in whether we have lives that are valuable to us: whether we achieve a sense of satisfaction or frustration from failing to achieve our goals (Levy 2014). Satisfaction and frustration need not feel like anything: they can be cashed out cognitively and in terms of functional properties. Is it really an inner glow that makes achieving a long-sought goal valuable? Or is it the knowledge that we've worked hard for it and overcome obstacles? Is it really 
a feeling that makes the death of a loved one bad? Or is it the knowledge that we'll never see them again? Phenomenal consciousness may contribute a great deal to the (dis)value of these states, but they are good or bad for us to some degree independently of how they feel.

Since it is not, or not only, the ways in which things feel for us that make them good or bad, we need not worry about the apparent ineffability of phenomenal consciousness. We can go a long way toward an inclusive animal ethics by studying only their cognition. Much of the evidence Mikhalevich \& Powell should therefore be seen as bearing directly on the moral status of arthropods, rather than as bearing on that status only by constituting evidence for their consciousness.

\section{References}

Baars, B. J. (2005) Global workspace theory of consciousness: Toward a cognitive neuroscience of human experience. Progress in Brain Research 150, 45-53.

Kahane, G., \& Savulescu, J. (2009) Brain damage and the moral significance of consciousness. Journal of Medicine and Philosophy 34(1), 6-26.

Levy, N. (2014) The value of consciousness. Journal of Consciousness Studies 21(1-2), 127-138.

Low, P., Panksepp, J., Reiss, D., Edelman, D., Van Swinderen, B., Low, P., \& Koch, C. (2012) The Cambridge Declaration on Consciousness.

Mikhalevich, I., \& Powell, R. (2020) Minds without spines: Evolutionarily inclusive animal ethics. Animal Sentience 29(1).

Seager, W. (2001) Consciousness, value and functionalism. Psyche 7.

Tononi, G., Boly, M., Massimini, M., \& Koch, C. (2016) Integrated information theory: From consciousness to its physical substrate. Nature Reviews Neuroscience 7, 450-461. 


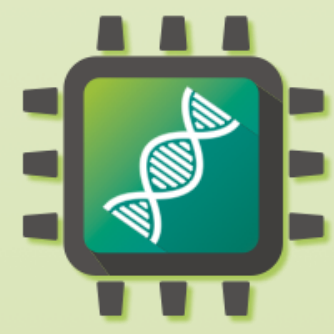

\section{Summer School 2020} INNOVATIVE SCIENCE WITHOUT ANIMALS

\section{June 22-26, 2020}

\section{Online Virtual Conference}

Calling all students and early-career researchers!

Join us for a FREE conference on innovative approaches in toxicology and biomedical sciences!

\section{This event features:}

- Lecture sessions about modern alternatives to the use of animals in toxicology and biomedical sciences

Virtual laboratory tours

E-poster presentations

Virtual engagement with speakers and attendees

Deadline to apply for the full program is June 10. Registration for individual lectures is available.

For more information visit InnovativeScience2020.org

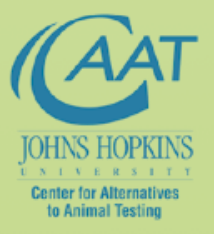

Physicians

Com

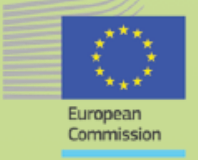

